\title{
Prevalence of Gallstones in Patients with Chronic Myelocytic Leukemia
}

\author{
Fehmi Ates $^{\text {a }}$ Mehmet Ali Erkurt $^{\mathrm{b}}$ Melih Karincaoglu ${ }^{\mathrm{a}}$ Murat Aladag $^{\mathrm{a}}$ \\ İsmet Aydogdub \\ Departments of ${ }^{\mathrm{a}}$ Gastroenterology and ${ }^{\mathrm{b}}$ Hematology, Inonu University School of Medicine, Malatya, Turkey
}

\section{Key Words}

Chronic myelocytic leukemia • Gallbladder stones •

Hemolysis

\begin{abstract}
Objective: The aim of the present case-control study was to determine whether or not the prevalence of gallbladder stones (GBS) was increased in patients with chronic myelocytic leukemia (CML) and to investigate clinical and laboratory characteristics of CML patients with GBS. Subjects and Methods: This study included 56 patients with CML and 55 sex- and age-matched healthy controls. All participants underwent abdominal ultrasonography and the main clinical and laboratory characteristics were recorded. Results: Gallbladder stones were detected in $13(23.6 \%)$ patients with $C M L$ and in $3(5.4 \%)$ control individuals $(p<0.05)$. The mean follow-up period of CML patients after diagnosis was 54.6 months, range 3-120 months. Hemoglobin levels were higher in the control group than in CML patients. However, total bilirubin, unconjugated bilirubin, lactate dehydrogenase levels, leukocyte and thrombocyte counts, frequency of splenomegaly and hepatomegaly were higher in the CML than in the control group $(p<0.05)$. Other clinical and laboratory values were not significantly different between the groups. CML patients with and without GBS were also compared for clinical and laboratory values. Age and follow-up
\end{abstract}

period of CML patients after diagnosis were higher in the $C M L$ patients with GBS $(p<0.05)$. Conclusions: Higher prevalence of GBS in CML patients than in healthy controls was detected. We suggest that CML may increase the frequency of GBS, apart from other well-known risk factors. This risk is probably related to increased unconjugated bilirubin, which determines hemolysis, older age and long follow-up period of CML patients after diagnosis.

Copyright $\odot 2009$ S. Karger AG, Basel

\section{Introduction}

Chronic myelocytic leukemia (CML), a clonal stem cell disorder characterized by increased proliferation of myeloid elements at all stages of differentiation [1], is principally a disease of adults with a yearly incidence of 1 in 100,000 in Western countries [2]. Its frequency increases with age and peaks at age 53 years [3]. Several clinical and laboratory findings such as minimal to moderate splenomegaly, mild hepatomegaly, and normochromic/normocytic anemia are found at the time of diagnosis of CML [4]. Abdominal ultrasonographic examination has sensitivity and specificity to detect gallbladder stones (GBS) ranging from 95 to $98 \%$ [5]. During routine evaluation of patients with CML, we observed that GBS have frequently been encountered in

\section{KARGER}

Fax +4161306 1234

E-Mail karger@karger.ch

www.karger.com
(C) 2009 S. Karger AG, Basel

1011-7571/09/0183-0175\$26.00/0

Accessible online at:

www.karger.com/mpp
Dr. Fehmi Ates

Gastroenteroloji Ünitesi

Malatya Devlet Hastanesi

TR-44300 Malatya (Turkey)

E-Maildrfehmiates@hotmail.com 
these patients during abdominal ultrasonographic examination.

The prevalence of GBS varies greatly among people of different ethnic origins. In the Western world, the frequency of GBS is about $10 \%$. In Turkey, the reported prevalence of GBS varies from 5.25 [6] to $10.5 \%$ in patients with gastrointestinal complaints and dyspepsia [7]. In many studies, GBS have been found to be related to sex, age, obesity, diabetes mellitus, pregnancy, use of oral contraceptives, genetic factors, intestinal diseases, cirrhosis and hemolytic diseases [8-13]. In this context, the prevalence of gallstones increases with age. GBS are more prevalent in females than males in adult age groups, with ratios exceeding 3:1 in women in their reproductive years and falling to under 2:1 in persons over 70 years old [5]. To our knowledge, there is no study reporting any increased frequency of GBS for patients with CML in the literature. Existing studies deal with the frequency and pathogenesis of GBS in patients with extramedullary or intramedullary hemolytic diseases, such as sickle cell anemia, thalassemia, spherocytosis and pernicious anemia which can frequently be encountered [14-19]. However, no studies are available on patients with CML. This observation prompted us to study whether or not there is an association in the prevalence of GBS in patients with CML by investigating clinical and laboratory characteristics of CML patients with GBS.

\section{Subjects and Methods}

\section{Study Population and Design}

Fifty-six patients with CML (29 males, 27 females, mean age $56 \pm 16$ years) and 55 age- and gender-matched healthy controls (28 males, 27 females, mean age $56 \pm 13$ years) were included in the study. Patients were recruited from consecutive CML patients who attended the Department of Hematology between January 1995 and December 2005. The CML patients and healthy controls did not have any metabolic disorders (diabetes mellitus, hypercholesterolemia, and hypertriglyceridemia), and/or obesity (body mass index $>30$ ), intestinal diseases, Gilbert's disease, cirrhosis, and hemolytic diseases. Neither the patients with CML nor the controls were pregnant, used oral contraceptives, or had valvular diseases of the heart. None had any history of gastrointestinal surgery.

The follow-up period of CML patients with GBS was defined as the time period from the initial diagnosis of CML to the initial diagnosis of GBS with routine abdominal ultrasonography. However, in CML patients without GBS, the follow-up period was defined as the time period from the initial diagnosis of CML to the last routine abdominal ultrasonography. The mean follow-up period of CML patients after diagnosis was 54.6 months in this study. During this period, clinical, laboratory and ultrasono- graphic findings were recorded by a staff hematologist and gastroenterologist together.

Routine ultrasonography was performed under fasting conditions with commercial gray-scale scanner devices (ATL HDI 3500 or Hitachi EUB 420) using a 3.5-MHz convex transducer. Two experienced operators (F.A. and M.K.) carried out all examinations and were not blinded as to whether subjects were CML patients or controls. The number and size of the GBS were not taken into consideration.

The study was approved by the local ethics committee and was performed according to the ethical standards recommended by the Helsinki Declaration.

\section{Statistical Analysis}

The data were expressed as mean \pm SD of the mean. Variable distribution was assessed by the Kolmogorov-Smirnov normality test. According to the variable distribution, unpaired Student's t test or Mann-Whitney test, one-way ANOVA or Kruskal-Wallis test was used, as appropriate. Correlations between different parameters were tested by Pearson correlation analysis, and $p$ values $<0.05$ were regarded as significant.

\section{Results}

The demographics, clinical, and laboratory characteristics of patients with CML and the control group are given in table 1 . Of the 56 patients with CML, GBS were detected in 13 (23.6\%) and in 3 (5.4\%) of the 55 healthy controls; the difference was statistically significant $(\mathrm{p}<$ $0.05)$.

GBS was detected with routine abdominal ultrasonography in only $3 \mathrm{CML}$ patients at the initial diagnosis of CML. Common bile duct dilatation, intra- or extrahepatic obstruction, gallbladder dilatation, pericholecystic fluid accumulation, or thickening of the gallbladder wall were not observed ultrasonographically in any of the CML patients or in the healthy controls. Hemoglobin levels were higher in the healthy controls than in CML patients, while total bilirubin, unconjugated bilirubin, lactate dehydrogenase (LDH) levels, leukocyte and thrombocyte counts, frequency of splenomegaly and hepatomegaly were higher in the CML group $(\mathrm{p}<0.05)$. Other clinical and laboratory values were not significantly different between the groups.

Comparison of the demographics, clinical and laboratory values of CML patients with and without GBS (table 2) showed that those with GBS were older and had a longer mean follow-up period after diagnosis than those without, and the difference was statistically significant $(\mathrm{p}<0.05)$. 
Table 1. Demographic, clinical, and laboratory characteristics of CML patients and healthy controls

\begin{tabular}{|c|c|c|c|}
\hline Variables & $\begin{array}{l}\text { CML } \\
(n=56)\end{array}$ & $\begin{array}{l}\text { Healthy } \\
\text { controls } \\
(\mathrm{n}=55)\end{array}$ & $\begin{array}{l}\mathrm{p} \\
\text { value }\end{array}$ \\
\hline Sex, men/women & $29 / 27$ & $28 / 27$ & NS \\
\hline Age, years & $56.2 \pm 16.1$ & $56.3 \pm 13.4$ & NS \\
\hline BMI & $23.6 \pm 2.7$ & $23.9 \pm 2.5$ & NS \\
\hline Total cholesterol, mg/dl & $151.8 \pm 24.8$ & $153.3 \pm 23.9$ & NS \\
\hline Triglyceride, mg/dl & $124.9 \pm 33.6$ & $128.1 \pm 33.3$ & NS \\
\hline $\mathrm{LDL}, \mathrm{mg} / \mathrm{dl}$ & $88.7 \pm 18.5$ & $88.7 \pm 18.5$ & NS \\
\hline $\mathrm{HDL}, \mathrm{mg} / \mathrm{dl}$ & $39.1 \pm 9.0$ & $39.6 \pm 8.9$ & NS \\
\hline VLDL, mg/dl & $24.7 \pm 56$ & $25.3 \pm 5.5$ & NS \\
\hline Albumin, g/dl & $4.1 \pm 0.5$ & $4.2 \pm 0.4$ & NS \\
\hline ALT, U/l & $20.0 \pm 17.3$ & $20.3 \pm 10.4$ & NS \\
\hline AST, U/1 & $24.2 \pm 15.1$ & $22.6 \pm 11.0$ & NS \\
\hline $\mathrm{LDH}, \mathrm{U} / \mathrm{l}$ & $1,071.3 \pm 791.2$ & $296.8 \pm 54.3$ & $<0.01$ \\
\hline \multicolumn{4}{|l|}{ Conjugated bilirubin } \\
\hline $\begin{array}{l}\text { Unconjugated bilirubin } \\
\mathrm{mg} / \mathrm{dl}\end{array}$ & $0.7 \pm 0.2$ & $0.3 \pm 0.2$ & $<0.01$ \\
\hline Hemoglobin, g/dl & $10.5 \pm 2.3$ & $13.9 \pm 1.1$ & $<0.01$ \\
\hline \multicolumn{4}{|l|}{ White blood cell count } \\
\hline $10^{3} / \mu \mathrm{l}$ & $91.4 \pm 119.1$ & $7.1 \pm 2.1$ & $<0.01$ \\
\hline Platelet count, $10^{3} / \mu \mathrm{l}$ & $408.1 \pm 296.0$ & $178.9 \pm 54.1$ & $<0.01$ \\
\hline Hepatomegaly, n & 25 & 1 & $<0.01$ \\
\hline Splenomegaly, n & 47 & 0 & $<0.01$ \\
\hline GBS, n & 13 & 3 & $<0.05$ \\
\hline
\end{tabular}

BMI = Body mass index; LDL = low-density lipoprotein; $\mathrm{HDL}$ = high-density lipoprotein; VLDL = very-low-density lipoprotein; ALT = alanine aminotransferase; AST = aspartate aminotransferase.

\section{Discussion}

GBS are one of the most common disorders seen in clinical practice. Most people with GBS (approximately $80 \%)$ are asymptomatic [14]. The clinical manifestations of GBS can include episodic pain, acute cholecystitis, and complications related to passage of GBS into the bile duct, including obstructive jaundice, cholangitis, and pancreatitis. Older age and increased life span with disease seem to favor the formation of GBS by providing a longer period of a low level of hemolysis and may explain the absence of past reports of high GBS formation in patients with CML who generally had a short life span. More studies are needed to confirm and completely explain this topic.

In the present study, GBS frequency and unconjugated bilirubin levels, which is an indicator of hemolysis, were
Table 2. Demographic, clinical, and laboratory characteristics of CML patients with and without GBS

\begin{tabular}{|c|c|c|c|}
\hline Variables & $\begin{array}{l}\text { CML patients } \\
\text { with GBS } \\
(\mathrm{n}=13)\end{array}$ & $\begin{array}{l}\text { CML patients } \\
\text { without GBS } \\
(\mathrm{n}=43)\end{array}$ & $\begin{array}{l}\mathrm{p} \\
\text { value }\end{array}$ \\
\hline Sex, men/women & $4 / 9$ & $25 / 18$ & NS \\
\hline Age, years & $72.3 \pm 0.4$ & $51.4 \pm 15.3$ & $<0.01$ \\
\hline $\begin{array}{l}\text { Follow-up period of } \\
\text { CML, months }\end{array}$ & $85.8 \pm 32.8$ & $45.2 \pm 28.1$ & $<0.01$ \\
\hline BMI & $23.4 \pm 3.1$ & $23.6 \pm 2.7$ & NS \\
\hline Total cholesterol, mg/dl & $150.0 \pm 25.3$ & $152.4 \pm 24.9$ & NS \\
\hline Triglyceride, mg/dl & $122.6 \pm 24.8$ & $125.5 \pm 36.1$ & NS \\
\hline $\mathrm{LDL}, \mathrm{mg} / \mathrm{dl}$ & $87.3 \pm 19.8$ & $89.7 \pm 18.3$ & NS \\
\hline $\mathrm{HDL}, \mathrm{mg} / \mathrm{dl}$ & $37.6 \pm 7.0$ & $39.6 \pm 9.5$ & NS \\
\hline VLDL, mg/dl & $25.0 \pm 5.4$ & $24.6 \pm 5.6$ & NS \\
\hline Albumin, $\mathrm{g} / \mathrm{dl}$ & $4.1 \pm 0.5$ & $4.1 \pm 0.4$ & NS \\
\hline ALT, U/l & $18.3 \pm 12.3$ & $21.1 \pm 18.5$ & NS \\
\hline AST, U/l & $18.4 \pm 6.8$ & $26.0 \pm 16.5$ & NS \\
\hline $\mathrm{LDH}, \mathrm{U} / \mathrm{l}$ & $1,210.8 \pm 456.0$ & $1,029.1 \pm 867.4$ & NS \\
\hline $\begin{array}{l}\text { Conjugated bilirubin } \\
\mathrm{mg} / \mathrm{dl}\end{array}$ & $0.1 \pm 0.1$ & $0.1 \pm 0.1$ & NS \\
\hline $\begin{array}{l}\text { Unconjugated bilirubin } \\
\mathrm{mg} / \mathrm{dl}\end{array}$ & $0.7 \pm 0.1$ & $0.7 \pm 0.3$ & NS \\
\hline Hemoglobin, g/dl & $10.1 \pm 2.0$ & $10.7 \pm 2.4$ & NS \\
\hline $\begin{array}{l}\text { White blood cell count } \\
10^{3} / \mu \mathrm{l}\end{array}$ & $80.9 \pm 89.1$ & $94.1 \pm 127.1$ & NS \\
\hline Platelet count, $10^{3} / \mu \mathrm{l}$ & $519.6 \pm 353.9$ & $374.1 \pm 272.9$ & NS \\
\hline Hepatomegaly, n & 6 & 19 & NS \\
\hline Splenomegaly, n & 13 & 34 & NS \\
\hline
\end{tabular}

BMI = Body mass index; LDL = low-density lipoprotein; $\mathrm{HDL}$ = high-density lipoprotein; VLDL = very-low-density lipoprotein; ALT = alanine aminotransferase; AST = aspartate aminotransferase.

significantly higher in CML patients than in the healthy group. This result simply may be explained with the hemolysis seen after development of splenomegaly and splenic sequestration in CML patients.

Older age and longer duration of disease are other striking findings of the present study. The survival of patients with CML has markedly increased with development of new chemotherapeutic agents like imatinib mesylate [20-22]. This leads to the development of some complications due to increased life span. Erythrocyte destruction occurs in patients with CML; however, this is at relatively low levels and did not lead to any complication due to short survival of patients in the past. But now, with extension of the life of CML patients, this relatively low rate but longer time of erythrocyte destruction may cause mild levels of chronic hyperbilirubinemia and a significant proportion of patients may be prone to GBS due to 
the resulting high biliary concentration of unconjugated bilirubin, which tends to coprecipitate with calcium in the gallbladder lumen [23]. Only 3 CML patients had GBS at the initial examination and this figure increased to 13 patients during the follow-up period. This remarkable increase also shows that longer follow-up of CML patients was an enabling factor in detecting GBS.

Generally, GBS are often a complication of diseases such as metabolic disorders (diabetes mellitus, hypercholesterolemia, and hypertriglyceridemia), and/or obesity, intestinal diseases, Gilbert's disease, cirrhosis, postvalvular replacement, and hemolytic diseases [8-13]. In liver cirrhosis, post-valvular replacement, and hemolytic diseases, bilirubin stone formation is enhanced due to bilirubin overproduction, caused mainly by hemolysis. Bilirubin stones form primarily in the gallbladder in sterile bile and are associated with advanced age. The pathogenesis of bilirubin stones is probably related to nonbacterial, nonenzymatic hydrolysis of bilirubin conjugates. At the $\mathrm{pH}$ of bile, this results in two monohydrogenated bilirubin anions that precipitate with calcium ions. Bilirubin monoconjugates, which are increased in several conditions, such as Gilbert's syndrome and chronic hemolysis, may play a pivotal role in bilirubin stone formation as a source of unconjugated monohydrogenated bilirubin and as a possible coprecipitant with calcium [23]. In our study, GBS in CML patients were asymptomatic, hence, cholecystectomy was not performed and therefore the content of the stones could not be clearly determined. However, since all the stones were in the gallbladder, and metabolic disorders and/or obesity (which are commonly risk factors for cholesterol stones) were not observed, and age and follow-up period were the only significant findings in our study, it can be surmised that all these stones were bilirubin pigment stones.

The significantly higher LDH levels in CML patients than in the control group obtained in our study could be similar to the increase in LDH in hemolytic diseases and carcinomatosis [24]. But, because we did not study LDH2 isozymes, which specifically increase in hemolysis, and because of the low specificity of a total LDH increase the suggested similarity of high levels of LDH in CML and hemolysis is not definitive.

The lower hemoglobin levels in CML patients than in the healthy control subjects of our study could be associated with the suppression of erythropoiesis because of the increased myelopoiesis and megakaryocytopoiesis, as may be expected in proliferative marrow-based processes. The severity of anemia is directly proportional to the degree of leukocytosis, and/or to hemolysis as a result of hepatosplenomegaly [25].

A major limitation of this study is that the ultrasonographers were not blinded to the diagnosis of the patients; hence, the possibility of bias in the outcome cannot be completely ruled out.

\section{Conclusion}

The present study showed an increased prevalence of GBS in CML patients compared to healthy controls. This is the first time this association has been made. However, previously it had been shown that GBS frequency might be increased with older age and longer follow-up period of CML patients due to their increased survival with new chemotherapeutic agents, especially with wide usage of imatinib mesylate.

\section{References}

1 Hehlmann R, Hochhaus A, Baccarani M, European LeukemiaNet: Chronic myeloid leukemia. Lancet 2007;370:342-350.

2 Sessions J: Chronic myeloid leukemia in 2007. Am J Health Syst Pharm 2007;64(24 suppl 15):S4-S9.

3 Goldman JM: Advances in CML. Clin Adv Hematol Oncol 2007;5:270-272.

4 Spiers AS, Bain BJ, Turner JE: The peripheral blood in chronic granulocytic leukemia: study of 50 untreated Philadelphia-positive cases. Scand J Haematol 1977;18:25-38.
5 Jacobson IM: Gallstones; in Grendell JH, McQuaid KR, Freidman SL (eds): Diagnosis and Treatment in Gastroenterology. London, Prentice-Hall, 1996, pp 668-670.

6 Beyler AR, Uzunalimoglu O, Gören A: Prevalence of gallbladder stones in Turkey. Turk J Gastroenterol 1993;4:434.

7 Beyler AR: Cholelithiasis and cholecystectomy incidence in dyspeptic patients. Turk J Gastroenterol 1988;9:257.

8 Bennion LJ, Grundy SM: Risk factors for the development of cholelithiasis in man (first of two parts). N Engl J Med 1978;299:11611167.
Caroli-Bosc FX, Pugliese P, Peten EP, Demarquay JF, Montet JC, Hastier P, Staccini P, Delmont JP: Gallbladder volume in adults and its relationship to age, sex, body mass index, body surface area and gallstones: an epidemiologic study in a nonselected population in France. Digestion 1999;60:344.

10 Conte D, Barisani D, Mandelli C, Bodini P, Borzio M, Pistoso S, Segala M, Aimo GP, Fraquelli M, Bianchi PA: Cholelithiasis in cirrhosis: analysis of 500 cases. Am J Gastroenterol 1991;86:1629-1632. 
11 Bargiggia S, Maconi G, Elli M, Molteni P, Ardizzone S, Parente F, Todaro I, Greco S, Manzionna G, Bianchi Porro G: Sonographic prevalence of liver steatosis and biliary tract stones in patients with inflammatory bowel disease: study of 511 subjects at a single center. J Clin Gastroenterol 2003;36:417-420.

12 Chaar V, Keclard L, Diara JP, Leturdu C, Elion J, Krishnamoorthy R, Clayton J, Romana M: Association of UGT1A1 polymorphism with prevalence and age at onset of cholelithiasis in sickle cell anemia. Haematologica 2005;90:188-193.

$\checkmark 13$ Borgna-Pignatti C, Rigon F, Merlo L, Chakrok R, Micciolo R, Perseu L, Galanello R: Thalassemia minor, the Gilbert mutation, and the risk of gallstones. Haematologica 2003;88:1106-1109.

14 Johnston DE, Kaplan MM: Pathogenesis and treatment of gallstones. N Engl J Med 1993; 328:412.

- 15 Everson GT, Nemeth A, Kourourian S, Zogg D, Leff NB, Dixon D, Githens JH, Pretorius D: Gallbladder function is altered in sickle hemoglobinopathy. Gastroenterology 1989; 96:1307-1316.
16 Kalayci AG, Albayrak D, Gunes M, Incesu L, Agaç R: The incidence of gallbladder stones and gallbladder function in beta-thalassemic children. Acta Radiol 1999;40:440-443.

17 Del Giudice EM, Perotta S, Nobili B, Specchia C, D’Urzo G, Iolascon A: Coinheritance of Gilbert syndrome increases the risk for developing gallstones in patients with hereditary spherocytosis. Blood 1999;94:22592262.

18 Galanello R, Piras S, Barella S, Leoni GB, Cipollina MD, Perseu L, Cao A: Cholelithiasis and Gilbert syndrome in homozygous $\beta$ thalassemia. Br J Haematol 2001;115:926928.

19 Aydogdu I, Sari R, Ulu R, Sevinc A: The frequency of gallbladder stones in patients with pernicious anemia. J Surg Res 2001;101:120123.

20 Kantarjian HM, O’Brien S, Cortes J, Giles F, Shan J, Rios MB, Faderl S, Verstovsek S, Garcia-Manero G, Wierda W, Kornblau S, Ferrajoli A, Keating M, Talpaz M: Survival advantage with imatinib mesylate therapy in chronic phase CML (CML-CP) after IFN- $\alpha$ failure and in late CML-CP, comparison with historical controls. Clin Cancer Res 2004;10:68-75.
21 Kantarjian HM, O’Brien S, Cortes J, Giles FJ, Rios MB, Shan J, Faderl S, Garcia-Manero G, Ferrajoli A, Verstovsek S, Wierda W, Keating M, Talpaz M: Imatinib mesylate therapy improves survival in patients with newly diagnosed Philadelphia chromosome-positive CML in the chronic phase. Cancer 2003;98: 2636-2642.

22 Kantarjian HM, Talpaz M, O’Brien S, Giles F, Faderl S, Verstovsek S, Garcia-Manero G, Shan J, Rios MB, Champlin R, de Lima M, Cortes J: Survival benefit with imatinib mesylate therapy in patients with acceleratedphase CML, comparison with historic experience. Cancer 2005;103:2099-2108.

23 Trotman BW: Pigment gallstone disease. Gastroenterol Clin North Am 1991;20:111126.

24 Karliner JS: Clinical usefulness and limitations of serum lactic dehydrogenase determinations. Clin Enzymol 1979;19:587.

25 Hyun BH, Gulati GL, Ashton JK: Myeloproliferative disorders: classification and diagnostic features with special emphasis on CML and AMM. Clin Lab Med 1990;10:825838 